\title{
ESTIMATING THE COST OF HEALTHCARE DELIVERY IN THREE HOSPITALS IN SOUTHERN GHANA
}

\author{
A. Q. Q. ABOAGYE ${ }^{1}$, A. N. K. DEGBOE ${ }^{2}$ and A. A. D. OBUOBI ${ }^{1}$ \\ ${ }^{1}$ University of Ghana Business School, Box LG 78, Legon and ${ }^{2}$ University Hospital, University of Ghana, \\ Legon, Ghana
}

Author for correspondence: Dr Anthony $Q . Q$. Aboagye

Email:qaboagye@ug.edu.gh

Conflict of interest: None declared

\begin{abstract}
SUMMARY
Objective: The cost burden (called full cost) of providing health services at a referral, a district and a mission hospital in Ghana were determined.

Methods: Standard cost-finding and cost analysis tools recommended by World Health Organization are used to analyse 2002 and 2003 hospital data. Full cost centre costs were computed by taking into account cash and non-cash expenses and allocating overhead costs to intermediate and final patient care centres.

Findings: The full costs of running the mission hospital in 2002 and 2003 were US\$600,295 and US\$758,647 respectively; for the district hospital, the respective costs were US\$496,240 and US\$487,537; and for the referral hospital, the respective costs were US\$1,160,535 and US\$1,394,321. Of these, overhead costs ranged between $20 \%$ and $42 \%$, while salaries made up between $45 \%$ and $60 \%$. Based on healthcare utilization data, in 2003 the estimated cost per outpatient attendance was US\$ 2.25 at the mission hospital, US\$ 4.51 at the district hospital and US\$8.5 at the referral hospital; inpatient day costs were US\$ 6.05, US\$ 9.95 and US\$18.8 at the respective hospitals. User fees charged at service delivery points were generally below cost. However, some service delivery points have the potential to recover their costs.

Conclusion: Salaries are the major cost component of the three hospitals. Overhead costs constitute an important part of hospital costs and must be noted in efforts to recover costs. Cost structures are different at different types of hospitals. Unit costs at service delivery points can be estimated and projected into the future.
\end{abstract}

Keywords: direct costs; overhead costs; intermediate costs; cost centres, cost allocation, hospitals, Ghana

\section{INTRODUCTION}

All over the world, healthcare systems are increasingly being tasked to improve the quality of health services and to reduce the rate of cost increases. Healthcare managers as well as policy-makers are seeking to better understand health system efficiencies by monitoring and evaluating the cost of healthcare provision at provider level. The World Health Organization (WHO) has contributed to these efforts by funding the development of manuals to aid the assessment of hospital costs beyond the traditional practice of evaluating health expenditure data without thorough analysis. ${ }^{1}$

Cost-finding and cost analysis refer to the processes through which financial and non-financial hospital data are disaggregated and manipulated to determine the costs of hospital services. Clearly, there are several reasons why cost analysis can contribute to improvement in the equity and efficiency of the healthcare system.

First, cost analysis helps determine whether health services delivery within a hospital deploy resources efficiently. Secondly, cost analysis information from different hospitals can be compared. Thirdly, cost analysis would enable cost performance to be monitored over time. Fourthly, policy-makers can rely on cost analysis information from several hospitals in determining how to standardize service delivery without compromising quality of care. Finally, cost analysis is important in determining reimbursement levels to hospitals funded by some form of health insurance.

For instance, Ghana is currently pursuing healthcare reform through the introduction of a national health insurance scheme to increase access to healthcare at affordable cost. For the scheme to be sustainable in the long-run, the scheme must refund to hospitals the full cost of delivering health services at various cost centers or departments.

The specific objectives of this study are 1) To estimate the overall costs (and components of costs) of providing health services at a referral, a district, and a mission hospital in Southern Ghana; 2) To allocate overhead costs to intermediate and direct patient-care centres for a more complete picture of costs at service delivery centres and to compute their unit costs; and 3) To compare user fees and unit costs of services. We 
hypothesize that i) overhead costs are substantial and should be countered in determining cost centre costs (not just direct costs) especially in cost recovery efforts, ii) cost structures differ by hospital and iii) user fees are a far cry from cost centre costs.

This research contributes to literature by providing a model that can be adopted to analyse and estimate full hospitals costs and unit costs in Ghana. It also alerts healthcare managers to areas which need further attention to capture information for cost analysis.

Cost analysis studies have not gained much ground in Africa, however a number have been undertaken in countries such as Malawi ${ }^{2}$, Egypt $^{3}$, South Africa ${ }^{4}$ and Ghana $^{5-6}$. The Malawian study analysed the cost of providing district health services with emphasis on a sample of six district hospitals. The study revealed that a relatively low proportion of district hospitals costs $(27 \%-39 \%)$ was spent on salaries and wages, while a relatively high proportion was spent on medical supplies $(24 \%-37 \%)$.

The Egyptian study analysed costs and efficiencies in that country's hospitals, using the step-down method to allocate the costs of overhead and intermediate services to final services departments. For one major hospital, annual personnel costs were $58 \%$ of total expenditures in $1993 / 1994$, while $14 \%$ of the total cost was on drugs and medical supplies.

The South African study analysed actual and estimated costs that are associated with treatment of patients at the inpatient, theatre and outpatient departments of five district hospitals. Using the top-down and step-down methods of overhead costs allocation, the investigators found, among others, that staff costs averaged $70 \%$ of departmental costs, and that high total costs did not imply high unit costs.

In a multi-nation study which estimated the unit cost of inpatient and outpatient care for hospitals in 49 countries it noted that unit costs of hospitals vary within countries. ${ }^{7}$ The two Ghanaian studies report utilization of hospital services and efficiencies over time and across hospitals, but not cost finding and analysis as done here.

This study undertook cost-finding and cost analysis using a methodology discussed in the WHO manual. ${ }^{1}$ Broadly, these steps involved identifying health services or products, describing cost centers, assigning inputs and their costs to their respective cost centers, allocating all overhead costs to intermediate and final costs centers and calculating total costs.
Here, actual and estimated data on hospital costs were used to approximate the full cost to the provider of delivering health services at intermediate and patientcare centres. Costs of personnel, equipment use, utilities, non-drug consumables and other costs incurred in the entire hospital system in the course of delivering services were captured. Overhead costs were then allocated by the step-down method, to patient-care and intermediate cost centres. Allocated costs together with the direct costs incurred at each service delivery point constitute the true or full cost of delivering service at the points in question from the service provider's perspective. ${ }^{1}$ That is, patient out-of-pocket expenses and opportunity costs are not counted.

Revenues generated were also estimated and compared to direct and allocated costs at various units. We are not aware that this type of exercise has been carried out in Ghana. With the estimate of the full historical cost of delivering service in hand, an inflation adjustment and an estimate of the number of patients to be served is all that is needed to arrive at the average cost per patient for the upcoming year.

\section{METHODS}

\section{Data Collection}

To begin work, the study proposal and data collection instrument were vetted and passed by the Ethical Review Committee of the Ghana Health Service. Then the study team visited each hospital and held meetings with relevant staff. The team reviewed organizational charts, charts of accounts and charts of cost centres for completeness, usability and conformity with the traditional administrative setup in Ghanaian hospitals. 8

Next, the data collection instrument (questionnaire) was discussed, tested and revised with input from hospital accounting and administrative staff. Training sessions were held for research assistants and hospital staff that were to help collect data. Data were captured for each cost centre at each hospital in respect of all costs borne in 2002 and 2003 as indicated next. Revenues generated at all revenue centres were also noted.

\section{Sampling}

This study focused on one district, one mission and one regional referral hospital. The hospitals were purposively sampled, due to budgetary and time constraints. Mindful of the different categories of hospitals in Ghana, the study sampled representative hospitals likely to be accessed by the typical Ghanaian. District and mission hospitals qualify on this criterion, for, designated district hospitals are the ones most widely available in the country. 
They are, by and large, fully fledged hospitals, and are government-owned and managed. Mission hospitals too are many and provide essentially the same level of services as district hospitals. They were established by churches as not-for-profit health institutions and are managed by them. They are however supervised by the government, which pays staff salaries and supplies equipment to them. However, mission hospitals use their links to the churches to gain additional access to equipment and medical personnel. In general, many mission hospitals are respected for what is perceived as higher dedication to duty.

Regional referral hospitals are another category. They provide specialist services that are not typically available at mission or district hospitals. They are a recent phenomenon in the healthcare system established by an Act of Parliament, Act 525, in 1996. They are fully managed and supervised by the government. Using their own knowledge of the Ghana health system, plus discussions with others including the Ghana Health Service, the researchers settled on the three hospitals to study. ${ }^{1}$ However, it is expected that once developed and operationalised, the model can easily be replicated for other hospitals.

We did not study private hospitals because there are few truly private hospitals in Ghana. Those that exist are concentrated in urban centres with limited scope of services. Also, many are unwilling to share their data. Teaching hospitals too were not studied because the time and resources required for such a study exceeded the budget and time available.

The following gives background information about hospitals studied (in 2003).

\begin{tabular}{|l|l|l|l|}
\hline & Mission & District & Referral \\
\hline Doctors & 9 & 3 & 16 \\
\hline Beds & 213 & 117 & 110 \\
\hline Admissions & 6,805 & 5,773 & 3,628 \\
\hline Outpatients & 41,390 & 16,311 & 35,501 \\
\hline Surgical operations & 6,872 & 898 & 1,960 \\
\hline Inpatient days & 59,796 & 22,507 & 26,364 \\
\hline
\end{tabular}

Further insight is given by the cost centres identified in Table 1. Costs and revenue data were captured at centres of activity corresponding to the hospitals' organizational and record keeping approaches.

\footnotetext{
${ }^{1}$ The health authorities would rather the hospitals sampled were not named. There were approximately 70 district, 40 mission and nine regional referral hospitals at the time.
}

The step-down method of cost analysis was then used to allocate overhead (administrative and centres not directly related to patient-care) costs to intermediate (diagnostic and patient support centres) and direct patient-care (outpatient, ward, theatre, etc.) centres. The total cost attributable to the intermediate and direct patient-care centres therefore becomes the sum of each of these centres' direct costs plus overhead costs allocated to them.

\section{The step-down approach}

The step-down approach is justified on grounds that resource flows in the three hospitals are generally in one direction. Cost centres were categorized as overhead, intermediate or direct patient-care centres based on the functions they perform. In the absence of data on actual administration costs attributable to target centres, the allocation criterion used to allocate overhead costs was each unit's share of person hours worked in the hospitals.

It is believed that this criterion reflects, as much as possible, the actual extent to which cost centres use overhead resources. This is in the same spirit as using shares of direct costs to allocate overheads. ${ }^{1}$ However, using hours worked in estimating the allocation statistic is more consistent with the manner in which the hours of nurses, doctors and staff who worked in more than one unit were allocated and costed among the units in which they worked as described under Labour costs below.

For each cost centre, this study documented the sum of the cost of salaries and wages and other expenses borne there as 'direct' costs. Next, 'direct' costs of the overhead departments were allocated to intermediate and direct patient-care centres. In all cases, the cost centre called administration serves the highest number of cost centres, so its costs were first distributed. The allocation statistic is the ratio of the number of hours worked in a target cost centre to the difference between total hours worked in the hospital and the hours worked in the administration department.

The amount allocated to the target centre is the product of this statistic and administration cost. Administration consisted of the following - medical, nursing and lay administration, maintenance, security, purchasing and supplies, transportation including ambulance, sanitation, hospital information system, apportioned utility and equipment costs and other costs. Details of these are provided below.

Following the allocation of administration costs, the sum of the direct costs incurred at the overhead cost centre that serves the next highest number of cost 
centres, laundry, plus costs allocated to this cost centre from administration are allocated next using a similarly computed allocation statistic (ratio of hours worked in a target cost centre to the difference between total hours worked in the hospital less hours worked in administration, less hours worked in the laundry department).

For the mission hospital, which did not have a hospital kitchen, these were the only overhead costs allocated. For the district and referral hospitals, kitchen costs were further allocated. Additionally, central services and supply department (CSSD) costs were further allocated for the referral hospital in like manner.

Note that only overhead costs were allocated, unlike studies which further allocate intermediate centre costs to patient-care centres. The rational is that the total costs of services consumed at the intermediate centres need to be known on their own for proper billing, etc. For example, in a typical Ghanaian hospital, one would be billed separately for laboratory, radiology, consultations and/or inpatient charges.

\section{Labour Cost}

As far as practicable, salaries and wages and related expenses of staff were attributed to the cost centres in which they worked. In situations where staff worked in more than one cost centre, their salaries were pro-rated and assigned to the different centres in the proportion of time spent at each cost centre. Total labour cost is the sum of salary and all salary related expenses.

\section{Non-drug consumables}

This category includes all manner of items that were consumed in the course of medical treatment at the OPD, ward, laboratory, other patient treatment centres, laundry, kitchen, etc. Gross annual amounts were provided by the accounting staff of each hospital. Each year's gross was allocated to cost centres in the ratio of the average amount consumed by each cost centre in February, May, August and November. Monthly amounts consumed were obtained by tracking movement of non-drug consumables from stores to the various cost centres. Four months were sampled because of budgetary and time constraints.

\section{Water and Electricity}

Hospital water and electricity bills are paid by District Assemblies, as a result none of the hospitals kept a complete record of their bills. There were however enough data to estimate total units consumed by each hospital. These were then converted to monetary amounts using the prevailing tariff rates.
The mission hospital did not incur water bills because it pumped water from a borehole into an overhead tank, treated it with chemicals, and distributed it by gravity. Thus, it only incurred the cost of water treatment chemicals and of pumping the water.

For each utility, each hospital had only one meter. To allocate the total to cost centres, hospital accounting, administrative and other knowledgeable staff were tasked to independently estimate the proportion of total costs that each cost centre must have consumed. The estimates from the different staff, which were generally consistent with each other, were averaged.

\section{Use of equipment}

Annual cost of using hospital biomedical and estate equipment at the various centres were not available and were estimated as follows. First, data on all major equipment at the various cost centres of the hospitals were collected. Next, for the district and mission hospitals, equipment costs were obtained by referring to the Ministry of Health's Standard Equipment List for District Hospitals. ${ }^{9}$

This list contains information on equipment type, quantity and unit costs in 1996 United States dollars (US\$), grouped by cost centre. The list contains equipment that the Ministry of Health expects the average district or mission hospital to have. The actual equipment on the ground was generally consistent with the standard list for the district/mission hospitals.

A variation of the Ministry of Health's Standard Equipment List for District Hospitals is available at the Ministry as a guide for regional referral hospitals. However, it turned out that the actual equipment on the ground at the referral hospital studied substantially exceeded what was on this second list. Thus, for the referral hospital, data available on the ground were used. Cost of these were obtained from the Ministry's list and equipment dealers.

Following this, the opinions of experts in hospital equipment, equipment managers, and the biomedical engineering unit of the Ministry of Health were solicited in respect of the lifespan of various categories of hospital equipment. Responses of respondents were then averaged. As it turned out, an average life span of eight years was obtained for electrical, electronic and combined electrical/electronic equipment.

Finally, straight line depreciation was computed to obtain the average annual amount of depreciation attributable to the use of equipment at each cost centre in 1996 US\$. Thus, this non-cash item was also included in cost centre 'direct' costs. 


\section{Transportation costs}

Each hospital kept a record of fuel consumption and vehicle repair costs. These together with estimated annual depreciation value of vehicles constituted the estimate of annual transportation cost. Record keeping was such that this item was wholly classified as administration.

\section{Equipment maintenance}

Hospitals recorded maintenance cost of equipment, machinery and plant. Here too, record keeping was such that this item was wholly classified as administration cost.

\section{Other costs}

This category includes telephone bills, postal bills, cost of printing and publication, hotel bills incurred by staff who traveled out-of-station, etc. Record keeping was such that this item was sometimes reported at cost centres, other times as administration cost.

It is noted that hospitals had no information in respect of the account labeled Investment or Infrastructure such as buildings (Item 4 of government account). Such expenditures are made by central government. Nor could one estimate depreciation amounts for this item since no historical nor market value estimates of these were available. To capture such costs, a major exercise beyond the scope of this study is required.

\section{Details of revenues}

Actual revenues generated per service rendered at the various centres from user fee charges ('cash and carry') were not available. However, total revenues generated at each hospital were. Estimates of revenues at revenue centres were obtained using available data.

For OPD, attendance figures broken down to male, female and children were available. The sum of the product of attendance and fee per attendance yielded estimates of OPD revenues. Revenue estimates for laboratory and radiology centres were estimated as the product of the number of investigations and the average of applicable unit fees for the different investigations that were conducted. The same approach was adopted in estimating revenues due to the theatres. Revenues attributable to the wards were estimated as the product of inpatient days and the applicable daily rates.

\section{RESULTS}

Table 1a reports the cost centres identified, the 'direct' costs, hours worked at each centre by all staff, allocation statistics for allocating administration and laundry costs, 'direct+allocated' costs and the ratio of the later to the 'direct' costs for the cost centres of the mission hospital for 2003. ${ }^{2}$ Monetary amounts are reported in 2003 United States dollars (US\$). The allocated amount to each receiving cost centre is the product of the allocation statistic and amount to be allocated. The average of the ratio of the sum of 'direct+allocated' cost to 'direct' costs for all cost centres in the hospital was $125 \%$. The range was $102 \%$, in the radiology, to $156 \%$, at the primary healthcare centre (PHC). The standard deviation was $17 \%$.

At the mission hospital (Table 1a), pharmarcy (including cost of drugs) was the most expensive to run in terms of 'direct' costs, followed by administration, theatre, and General OPD in that order. Radiology was least expensive followed by $P H C$. Note that under the 'cash and carry' system, drugs were fully paid for by patients. After overheads were allocated, the theatre at the mission hospital was the most expensive to run, followed by pharmacy, then children's ward, then General OPD. Radiology was least, followed by Laboratory then $P H C$.

Table $1 \mathrm{~b}$ reports findings similar to Table $1 \mathrm{a}$ but for the district hospital. Note that for this hospital, three overhead costs were allocated - administration, laundry and kitchen costs. The average of the ratio of the sum of 'direct+allocated' cost to 'direct' costs for all centres was $152 \%$, with a range of $133 \%$, in the theatre, to $206 \%$, at the Male ward and a standard deviation of $55 \%$. These ratios are higher than for the mission hospital, but one notes that more overhead costs were allocated here.

At the district hospital (Table 1b), administration was most expensive to run in terms of 'direct' costs, followed by pharmacy (including cost of drugs), maternity ward, and General $O P D$ in that order. Mortuary was least expensive followed by $P H C$. After overheads were allocated, the pharmacy became the most expensive to run, followed by maternity ward, General OPD, then male ward. Mortuary was least still expensive.

Table 1c reports the corresponding findings for the referral hospital. Note that for this hospital, four overhead costs were allocated - administration, laundry, kitchen and central services and supply department (CSSD).

The average of the ratio of the sum of 'direct+allocated' cost to 'direct' costs for all centres was $199 \%$, with a range of $135 \%$, in the Radiology

\footnotetext{
${ }^{2}$ Administration and laundry are the only overhead cost centres. The hospital does not serve meals, and maintains only an overnight cold room for corpses.
} 
centre, to $330 \%$, at the General $O P D$ and a standard

they are for the other hospitals.

deviation of $44 \%$. Clearly, these ratios are higher than

Table 1a: Stepping-down the Mission hospital's 2003 overhead costs

\begin{tabular}{|c|c|c|c|c|c|c|}
\hline COST CENTRE & $\begin{array}{c}\text { Direct } \\
\text { Cost }\end{array}$ & & $\begin{array}{l}\text { Admini- } \\
\text { stration }\end{array}$ & Laundry & \multirow[b]{2}{*}{$\begin{array}{l}\text { Direct allo- } \\
\text { cated }^{+}\end{array}$} & \multirow[b]{2}{*}{ RATIO* } \\
\hline OVERHEAD & US\$ & Hours & $\begin{array}{l}\text { Alloc. } \\
\text { Stat }^{@}\end{array}$ & Alloc. Stat ${ }^{\circledR}$ & & \\
\hline Administration & 110,593 & 150,392 & & & & \\
\hline Laundry & 30,593 & 27,160 & $6 \%$ & & & \\
\hline \multicolumn{7}{|l|}{ INTERMEDIATE } \\
\hline Pharmacy $^{+}$ & 113,302 & 9,024 & $2 \%$ & $2 \%$ & 116,316 & $103 \%$ \\
\hline Drugs & 97,621 & & & & & \\
\hline Laboratory & 21,506 & 10,040 & $2 \%$ & $2 \%$ & 24,860 & $116 \%$ \\
\hline Radiology & 14,094 & 824 & $0 \%$ & $0 \%$ & 14,369 & $102 \%$ \\
\hline \multicolumn{7}{|c|}{ DIRECT PATIENT-CARE } \\
\hline General OPD & 76,926 & 58,772 & $13 \%$ & $14 \%$ & 96,557 & $126 \%$ \\
\hline Theatre & 103,792 & 48,972 & $11 \%$ & $12 \%$ & 120,150 & $116 \%$ \\
\hline \multicolumn{7}{|l|}{ WARDS } \\
\hline Male & 62,771 & 54,720 & $12 \%$ & $13 \%$ & 81,049 & $129 \%$ \\
\hline Female & 69,433 & 62,686 & $14 \%$ & $15 \%$ & 90,371 & $130 \%$ \\
\hline Children & 69,934 & 89,568 & $20 \%$ & $21 \%$ & 99,852 & $143 \%$ \\
\hline Maternity & 55,587 & 54,720 & $12 \%$ & $13 \%$ & 73,865 & $133 \%$ \\
\hline Primary Health Care & 19,835 & 33,360 & $7 \%$ & $8 \%$ & 30,978 & $156 \%$ \\
\hline Average & & & & & & $125 \%$ \\
\hline Total & 748,366 & 600,238 & $100 \%$ & $100 \%$ & 748,366 & \\
\hline
\end{tabular}

Legend: ${ }^{@}$ Allocating statistic; ${ }^{*}$ ratio of 'Direct+Allocated' costs to 'Direct' costs; ${ }^{+}$Includes cost of drugs.

At the referral hospital (Table 1c), administration was most expensive to run in terms of 'direct' costs by a wide margin, followed by pharmacy (including cost of drugs), theatre, and Accident \& Emergency and Total $O P D$ in that order. ${ }^{3}$ Physiotherapy was least expensive followed by $P H C$. After overheads were allocated, the pharmacy was now the most expensive to run, followed again by theatre, Accident and Emergency, then Total OPD. Physiotherapy was still the least expensive, followed by $P H C$.

\section{Unit costs}

Using the background information provided for each hospital earlier, the following average unit costs are estimated for 2003 in US\$:

${ }^{3}$ This referral hospital has many specialist OPDs - General, ENT, Eye, Obstetrics and Gynecology, Dental and Psychiatry. Here we grouped them as 'Total OPD'.

\begin{tabular}{|l|l|l|l|}
\hline & Mission & District & Referral \\
\hline OPD & 2.25 & 4.51 & 8.50 \\
\hline Inpatient day & 6.05 & 9.95 & 18.80 \\
\hline Theatre & 20.45 & 13.32 & 94.88 \\
\hline
\end{tabular}

The relatively higher OPD rate at the district hospital is due to the much lower attendance rate, while it's relatively lower theatre rate is due to the fact that the theatre is not heavily equipped and is not used regularly. The relatively higher theatre rate at the referral hospital is due to its more expensive modern equipment and higher cost of surgical specialists. 
Table 1b: Stepping-down the District hospital's 2003 overhead costs

\begin{tabular}{|c|c|c|c|c|c|c|c|}
\hline COST CENTRE & $\begin{array}{l}\text { Direct } \\
\text { Cost }\end{array}$ & & $\begin{array}{l}\text { Adminis } \\
\text { tration }\end{array}$ & Laundry & Kitchen & \multirow{2}{*}{$\begin{array}{l}\text { Direct }^{+} \\
\text {Allocated } \\
\text { costs US\$ }\end{array}$} & \multirow[b]{2}{*}{ RATIO* } \\
\hline OVERHEAD & US\$ & Hours & Alloc. Stat & $\begin{array}{l}\text { Alloc. } \\
\text { Stat }\end{array}$ & Alloc. Stat & & \\
\hline Administration & 151,992 & 130,086 & & & & & \\
\hline Laundry & 8,700 & 10,840 & $4 \%$ & & & & \\
\hline Kitchen & 9,480 & 19,020 & $6 \%$ & $6 \%$ & & & \\
\hline \multicolumn{8}{|l|}{ INTERMEDIATE } \\
\hline Pharmacy $^{+}$ & 119,474 & 34,420 & $11 \%$ & $12 \%$ & $12 \%$ & 140,409 & $118 \%$ \\
\hline Drugs & 94,847 & & & & & 94,847 & \\
\hline Laboratory & 11,993 & 11,190 & $4 \%$ & $4 \%$ & $4 \%$ & 18,799 & $157 \%$ \\
\hline Radiology & 13,297 & 8,480 & $3 \%$ & $3 \%$ & $3 \%$ & 18,454 & $139 \%$ \\
\hline Mortuary & 5,111 & 10,840 & $4 \%$ & $4 \%$ & $4 \%$ & 11,704 & $229 \%$ \\
\hline \multicolumn{8}{|c|}{ DIRECT PATIENT-CARE } \\
\hline General OPD & 39,794 & 36,486 & $12 \%$ & $12 \%$ & $13 \%$ & 61,986 & $156 \%$ \\
\hline Theatre & 35,665 & 19,164 & $6 \%$ & $6 \%$ & $7 \%$ & 47,321 & $133 \%$ \\
\hline \multicolumn{8}{|l|}{ WARDS } \\
\hline Male & 25,475 & 44,554 & $14 \%$ & $15 \%$ & $16 \%$ & 52,573 & $206 \%$ \\
\hline Female & 25,858 & 29,544 & $10 \%$ & $10 \%$ & $11 \%$ & 43,827 & $169 \%$ \\
\hline Children & 23,612 & 29,488 & $10 \%$ & $10 \%$ & $11 \%$ & 41,547 & $176 \%$ \\
\hline Maternity & 41,913 & 44,554 & $14 \%$ & $15 \%$ & $16 \%$ & 69,012 & $165 \%$ \\
\hline $\begin{array}{l}\text { Primary Health } \\
\text { Care }\end{array}$ & 8,812 & 11,070 & $4 \%$ & $4 \%$ & $4 \%$ & 15,545 & $176 \%$ \\
\hline Average & & & & & & & $152 \%$ \\
\hline Total & 521,176 & 439,736 & $100 \%$ & $100 \%$ & $100 \%$ & 521,176 & \\
\hline
\end{tabular}

Legend: ${ }^{@}$ Allocating statistic; * ${ }^{*}$ ratio of 'Direct+Allocated' costs to 'Direct' costs; ${ }^{+}$Includes cost of drugs.

\section{Total running costs}

Table 2 reports the total running costs of the three hospitals (excluding building and investments as discussed earlier) and proportions of salaries, overhead costs, intermediate costs and direct patient-care costs. The table says that the total cost of running the mission hospital (including cost of drugs) in 2002 was US\$ 604,938 . Of this amount, salary and related expenses made up 60\%. In 2003 the total was US\$755,814, an increase of $25 \%$ over the 2002 total in nominal terms with salaries making up $56 \%$. Direct costs incurred at direct patient-care centres constituted $60 \%$ of the total cost of running the hospital in each year, intermediate centres made about $20 \%$, and overhead another $20 \%$.

Table 2 also says that the total cost of running the district hospital in 2002 was US\$493,827. Salary and related expenses made up $45 \%$. For 2003 , the total cost was US\$488,372, a nominal decrease (1\%) over the 2002 total with salaries making up 52\%. Table 2 also suggests that direct costs incurred at direct patient-care centres constituted about $40 \%$ of the total cost of running the hospital in each of 2002 and 2003, intermediate centres made up 31\% and 24\% in 2002 and 2003 respectively, and overhead costs $29 \%$ and $35 \%$ in 2002 and 2003 respectively.

Table 2 further reports that the total cost of running the referral hospital in 2002 was US\$ 1,160,494. Salary and related expenses made up 47\%. For 2003 the total cost was US\$1,395,349, a nominal increase of $20 \%$ over 2002. Direct costs incurred at direct patient-care centres constituted about $39 \%$ of the total cost of running the hospital in each year, intermediate centres made up about $20 \%$, and overhead costs $42 \%$ in each year. 

Table 1c: Stepping-down the Referral hospital's 2003 overhead costs

\begin{tabular}{|c|c|c|c|c|c|c|c|c|}
\hline COST CENTRE & $\begin{array}{l}\text { Direct } \\
\text { Cost }\end{array}$ & & $\begin{array}{l}\text { Ad- } \\
\text { minis- } \\
\text { tration }\end{array}$ & $\begin{array}{l}\text { Laun- } \\
\text { dry }\end{array}$ & Kitchen & CSSD & & \\
\hline OVERHEAD & US\$ & Hours & $\begin{array}{l}\text { Alloc. } \\
\text { Stat }\end{array}$ & $\begin{array}{l}\text { Alloc. } \\
\text { Stat }\end{array}$ & $\begin{array}{l}\text { Alloc } \\
\text { Stat }\end{array}$ & $\begin{array}{l}\text { Alloc. } \\
\text { Stat }\end{array}$ & $\begin{array}{l}\text { Direct+ } \\
\text { Allocated }\end{array}$ & $\begin{array}{l}\text { RA- } \\
\text { TIO* }\end{array}$ \\
\hline Administration & 507,031 & 415,760 & & & & & & \\
\hline Laundry & 33,433 & 37,840 & $6 \%$ & & & & & \\
\hline Kitchen & 39,211 & 58,160 & $10 \%$ & & & & & \\
\hline CSSD & 9,550 & 17,520 & $3 \%$ & & & & & \\
\hline \multicolumn{9}{|l|}{ INTERMEDIATE } \\
\hline Pharmacy $^{+}$ & 185,129 & 47,360 & $8 \%$ & $8 \%$ & $9 \%$ & $10 \%$ & 242,607 & $131 \%$ \\
\hline Drugs & 143,364 & & & & & & & \\
\hline $\begin{array}{ll}\text { Laboratory } & \& \\
\text { Blood Bank } & \\
\end{array}$ & 56,824 & 38,720 & $6 \%$ & $7 \%$ & $8 \%$ & $8 \%$ & 103,817 & $183 \%$ \\
\hline Radiology & 25,247 & 7,200 & $1 \%$ & $1 \%$ & $1 \%$ & $1 \%$ & 33,985 & $135 \%$ \\
\hline Mortuary & 15,258 & 13,120 & $2 \%$ & $2 \%$ & $3 \%$ & $3 \%$ & 31,181 & $204 \%$ \\
\hline Physiotherapy & 4,345 & 3,680 & $1 \%$ & $1 \%$ & $1 \%$ & $1 \%$ & 8,811 & $203 \%$ \\
\hline \multicolumn{9}{|c|}{ DIRECT PATIENT-CARE } \\
\hline TOTAL OPD & 64,946 & 67,496 & $10 \%$ & $0 \%$ & $0 \%$ & $0 \%$ & 146,862 & $226 \%$ \\
\hline $\begin{array}{l}\text { Accident \& Emer- } \\
\text { gency OPD/Ward }\end{array}$ & 90,246 & 62,312 & $10 \%$ & $11 \%$ & $12 \%$ & $13 \%$ & 165,871 & $184 \%$ \\
\hline Theatre & 125,117 & 64,930 & $11 \%$ & $12 \%$ & $13 \%$ & $13 \%$ & 203,919 & $163 \%$ \\
\hline \multicolumn{9}{|l|}{ WARDS } \\
\hline Male & 63,006 & 45,684 & $8 \%$ & $8 \%$ & $9 \%$ & $9 \%$ & 118,450 & $188 \%$ \\
\hline Female & 59,456 & 40,684 & $7 \%$ & $7 \%$ & $8 \%$ & $8 \%$ & 108,832 & $183 \%$ \\
\hline Children & 38,829 & 36,138 & $6 \%$ & $6 \%$ & $7 \%$ & $7 \%$ & 82,688 & $213 \%$ \\
\hline Maternity & 66,320 & 51,776 & $9 \%$ & $9 \%$ & $10 \%$ & $11 \%$ & 129,158 & $195 \%$ \\
\hline $\begin{array}{l}\text { Primary Health } \\
\text { Care }\end{array}$ & 4,842 & 6,400 & $1 \%$ & $1 \%$ & $1 \%$ & $1 \%$ & 12,610 & $260 \%$ \\
\hline Average & & & & & & & & $199 \%$ \\
\hline Total & $1,388,789$ & $1,014,780$ & $99 \%$ & $88 \%$ & $87 \%$ & $86 \%$ & $1,388,789$ & \\
\hline
\end{tabular}

Legend: ${ }^{@}$ Allocating statistic; ${ }^{*}$ ratio of 'Direct+Allocated' costs to 'Direct' costs; ${ }^{+}$Includes cost of drugs.

Table 2 Total Hospital Costs in US\$ showing components

\begin{tabular}{|l|l|l|l|l|l|l|}
\hline & \multicolumn{2}{|c|}{ Mission } & \multicolumn{2}{c|}{ District } & \multicolumn{2}{c|}{ Referral } \\
\hline COST CATEGORY & $\mathbf{2 0 0 2}$ & $\mathbf{2 0 0 3}$ & $\mathbf{2 0 0 2}$ & $\mathbf{2 0 0 3}$ & $\mathbf{2 0 0 2}$ & $\mathbf{2 0 0 3}$ \\
\hline Total Hospital Costs* & 600,295 & 758,647 & 496,240 & 487,534 & $1,160,535$ & $1,394,321$ \\
\hline Salaries & $60 \%$ & $56 \%$ & $45 \%$ & $52 \%$ & $47 \%$ & $50 \%$ \\
\hline Other Expenses (no drugs) & $29 \%$ & $31 \%$ & $35 \%$ & $35 \%$ & $45 \%$ & $40 \%$ \\
\hline Cost of Drugs & $11 \%$ & $13 \%$ & $20 \%$ & $13 \%$ & $8 \%$ & $10 \%$ \\
\hline Total Overhead Costs & $21 \%$ & $20 \%$ & $29 \%$ & $35 \%$ & $42 \%$ & $42 \%$ \\
\hline Total Intermediate Costs & $19 \%$ & $20 \%$ & $31 \%$ & $24 \%$ & $19 \%$ & $20 \%$ \\
\hline Total Direct Patient-care & $60 \%$ & $60 \%$ & $40 \%$ & $41 \%$ & $39 \%$ & $38 \%$ \\
\hline
\end{tabular}


Table 3 Ratio of revenues to the sum of direct and allocated costs

\begin{tabular}{|l|c|c|c|c|c|c|}
\hline & \multicolumn{2}{|c|}{ Mission } & \multicolumn{2}{c|}{ District } & \multicolumn{2}{c|}{ Referral } \\
\hline & $\mathbf{2 0 0 2}$ & $\mathbf{2 0 0 3}$ & $\mathbf{2 0 0 2}$ & $\mathbf{2 0 0 3}$ & $\mathbf{2 0 0 2}$ & $\mathbf{2 0 0 3}$ \\
\hline Laboratory/Blood Bank & $203 \%$ & $232 \%$ & $207 \%$ & $152 \%$ & $43 \%$ & $44 \%$ \\
\hline Radiology & $38 \%$ & $38 \%$ & $28 \%$ & $44 \%$ & $27 \%$ & $24 \%$ \\
\hline General OPD & $45 \%$ & $47 \%$ & $28 \%$ & $27 \%$ & $78 \%$ & $81 \%$ \\
\hline Theatre & $185 \%$ & $166 \%$ & $31 \%$ & $26 \%$ & $14 \%$ & $15 \%$ \\
\hline Male & $12 \%$ & $8 \%$ & $23 \%$ & $21 \%$ & $15 \%$ & $16 \%$ \\
\hline Female & $11 \%$ & $8 \%$ & $20 \%$ & $18 \%$ & $12 \%$ & $15 \%$ \\
\hline Children & $3 \%$ & $2 \%$ & $12 \%$ & $10 \%$ & $11 \%$ & $11 \%$ \\
\hline Maternity Ward & $24 \%$ & $13 \%$ & $11 \%$ & $10 \%$ & $12 \%$ & $14 \%$ \\
\hline Accident/Emergency & & & & & $5 \%$ & $6 \%$ \\
\hline
\end{tabular}

\section{Revenues versus costs}

We estimated revenues for the centres for which data were available as described under methodology and then computed the ratios of revenues to 'direct+allocated' costs just calculated. At the mission hospital, revenues at the laboratory and theatre exceeded the costs incurred at those centres in both years (Table 3). At the district hospital, revenues exceeded costs at the laboratory only. At the referral hospital, revenues were less than costs at all cost centres.

\section{DISCUSSION}

The conceptualization of this paper was to estimate the costs that representatives of three categories of hospitals incur at various cost centres counting both cash and non-cash expenses, and to allocate costs incurred at overhead centres to those centres that serve patients so as to obtain the full cost of running patientcare centres. That, in US\$ terms, costs of intermediate and direct patient-care centres increase by an average of as much as $25 \%$ at the mission hospital, $52 \%$ at district hospital and 99\% when overhead costs are allocated, says that it is important to consider overhead costs in arriving at user fees that patients or insurers may pay if cost recovery is an objective. Policy makers in Ghana now have empirical indication of full costs.

The South African study alluded to earlier, indicates the proportion of direct costs in 'direct+allocated' OPD, theatre and inpatient costs at district hospitals. The implied proportions of 'direct+allocated' costs to direct cost are 167\% for OPD, 154\% for theatre and $145 \%$ in the inpatient department. For the sole district hospital in our study the corresponding ratios are $156 \%, 133 \%$ and $175 \%$ respectively. One notes that the two sets of figures are not entirely inconsistent.
Further, in all cases, allocation of overhead costs changed the ranking of many cost centres from their ranking when only direct costs are considered.

Comparing the proportions of costs that are salaries to other studies, salaries in the Zambian study referred to earlier are a lower proportion of recurrent costs, $27 \%$ $39 \%$, than the $45 \%-60 \%$ of running costs identified here, which is itself less than the $70 \%$ identified in the South African study. No conclusions can however be drawn about these figures in the absence of further information about the different health systems and quality of care. Comparison with the two Ghanaian studies cited is not appropriate.

In all, the differences in allocating statistics (Table 1a, $1 \mathrm{~b}$, and 1c) and in the proportions indicated in Table 2 and Table 3 suggest that cost structures differ among hospital types. This should be borne in mind during policy formulation. Additional observations are worth noting here:

- The theatre at the mission hospital has a reputation for providing excellent surgical services and feminine care and receives high patronage.

- The high cost of drugs was not a big burden on hospitals since patients paid directly for their medication.

- Primary health centre costs were low partly because many of their programs, such as vaccinations and outreach, are funded directly by government and do not pass through hospital budgets.

- At the mission hospital, salaries and related expenses make up a higher proportion of total costs compared to the other hospitals because unlike the other two, the semi-autonomous mission hospital pays an extra salary allowance to attract and retain staff. 
Obviously, the referral hospital is the most expensive because of its higher number of employees of all categories and higher equipment depreciation costs. This study did not address the question of quality of healthcare or health outcomes.

\section{CONCLUSION}

This study shows that with painstaking effort hospital cost centres' non-cash expenses can be estimated. Salaries are the major cost component of the three hospitals studied. Overhead costs constitute an important part of hospital costs and must be noted in efforts to recover costs. Cost structures are different for different hospital types. User fees in effect under "cash and carry" were generally well below costs. Using the indicative full unit costs of the OPD, inpatient and theatre cases reported, an adjustment for expected inflation (exchange rate) for the upcoming year is all that is needed to estimate future unit costs.

\section{ACKNOWLEDGEMENT}

This study was carried out with financial assistance from the Ghanaian-Dutch Collaboration Programme For Health Research And Development Under Contract Number $2003 / G D / 33$. We are grateful to the medical superintendents and staff of the three hospitals studied.

\section{REFERENCES}

1. Shepard DS, Hodgkin D and Anthony YE, Analysis of Hospital Costs: A Manual for Managers, 2002, WHO, Geneva.

2. Mills, AJ, Kapalamula, J and Chisimbi, S, The Cost of District Hospital: A Case Study in Malawi, Bulletin of the World Health Organization, 1993; $71: 329-339$.
3. Department Of Planning, Ministry Of Health And Population, Harvard School Of Public Health, University Of California, Berkeley, School Of Public Health, Cost Analysis and Efficiency Indicators for Health Care: Report Number 1, Summary Output for Bani Suef General Hospital, 1993-1994, 1997.

4. Dawkinun, D, Jikwana, S, Setagane, S, Maclou, B, and Mabusela D, Estimating the Cost of District Hospital Services, 2002. A Report retrieved February 9, 2010

http://www.doh.gov.za/doc/reports/2002/findcreport01.pdf

5. Adam, T, Evans, DB and Murray, CJL, Econometric Estimation of Country-Specific Hospital Costs, Cost Effectiveness and Resource Allocation 2003; 23; 1(3). Published online 2003, February 26. http://www.doh.gov.za/doc/reports/2002/findcreport01.pdf

6. Adams, I, Darko, D and Accorsi, S, Utilization of Hospital Services in Ghana: A Review of Hospital Performance in the last five years. Information for Action: A Bulletin of Health Information, 2001, July - Sept, Ministry of Health, Accra.

7. Adams, D, Accorsi, S, Essegbey, I, Bayensi, F, and Darko, D, Comparative Analysis of Three Hospitals in Ghana: Patterns of Utilisation of inpatient Services. Information for Action: A Bulletin of Health Information, 2001, July - Sept, Ministry of Health, Accra.

8. Ackon, E. K., Management of Healthcare Organisations, 2001, Bel-Team Publications Ltd, Accra.

9. Ministry of Health, Standard Equipment List for District Hospitals, 1997, Accra 